\title{
An Academic Report on Mobile Application Development: Creating an Extra Field Practice Platform for Young Players
}

\author{
Amanda Miranda Cunha de Moura and Christian Bach
}

\begin{abstract}
In this study, we deploy the impact of Education, Social Media, Motivation, and Virtual Reality on Mobile application development. The mission of mobile application development studies is to advance the understanding of this technology in order to use it in favor of children with learning difficulties, young athletes seeking extra field coaching, and parents concerned with their children development. The primary goal of this study was to investigate the user's habits, motivations and technical possibilities in order to develop mobile learning and coaching activities in the e-environment process. The Smart Sport app is dedicated to provide these target market with the proper tool of electronic coaching.

This paper aims to review 70 researchers and their articles about how the above assets affect directly the mobile application design. By doing so, it re-investigate the relationship between existing demand opportunities and the future of the application technology, considering that the mobile applications environment has a multitude of particularities generated by the complex system of devices, hardware, and software profiles and categories of users. Using the grounded theory, a model was developed and evaluated based on how Motivation, Education, Social Media Network, and Virtual Reality affects the development of mobile applications using data from JSTOR and Academic Search Premier database.
\end{abstract}

Index Terms-Education; Social Media; Motivation; Virtual Reality; Learning; Electronic coaching; Opportunities; Demand; Software/Devices; e-Environment; Performance; Innovation.

\section{INTRODUCTION}

There is growing literature on mobile application development [1]. Apps and gadgets are not new to our society, however recent studies have been conducted to implement new factors of influence behind the existing features. If properly designed, mobile application can guarantee competitive advantage in the market because the demand for digital products has increased significantly in the past few years. New types of devices, like tablets with its evolved interface from button-click to touch-screen, has opened new perspectives in the human-computer interaction for both users and software designers [2]. It is my main argument that mobile application will be an extra

Published on December 3, 2016.

Amanda Miranda Cunha de Moura , M.S. Department of Technology Management, School of Business, University of Bridgeport, Bridgeport, CT 06604 USA (email: ammirand@my.bridgeport.edu).

Christian Bach, Ph.D., Assistant Professor. Department of Technology Management, School of Engineering, University of Bridgeport, Bridgeport, CT 06604 USA (email: cbach@bridgeport.edu). classroom/field tool for both students and athletes seeking to strive for greatness. Due to the increasing demand for technology and digital devices, the mobile app fits as the most accessible platform capable to provide dynamic learning, quick feedback, rewards programs, and insert/engage the user in a parallel world of learning [3-5]. This work intent to discuss how my mobile app Smart Sport will revolutionize American youth soccer by proving one of the most complete tools for extra field training.

The research is relevant, comprehensive, and transparent in explaining the correlation between the four variables and the main goal. My preferred approach is to state one by one influences and relations to the app design [6,7]. The fast adoption of smartphones, tablet computers and other mobile devices have allowed new opportunities for consumers to interact with others or go electronic shopping, and also capture information anywhere in the world based on GPS services. Therefore, consumers are more active and informed at the same time. These trends are closely linked to the changes of consumers' needs and behavior [8]. Those changes are what this paper will dig to promote true delivery of an electronic platform capable to offer the user's leverage of performance in both academic and athletic standards. Furthermore, this study provides a rich construction of an instrument for mobile application efficiency that can serve as a "first-mover" element for future work to understand the impacts of mobile application usability and can be used as reference to develop new effective mobile apps [9]. This paper will not only permit the progress of existing mobile devices, but will allow the future development of every time tighter relations between education, motivation, social media, and virtual reality to the app development processes [10-12]. Because the users are affectionate about their electronic devices, they will benefit directly from the outcomes associated with learning through it, therefore, they will be more likely to cope in future researches, they will more likely to adapt to future learning apps, and they will engage in “fun” learning environments, increasing society's overall number of children committed to classrooms and sports.

Technology is as much a product of social construction as of technical innovation and this evaluation research could successfully define my social construction goal as the leveraging of soccer playing on the distance, at any time [13]. There is an entire enterprise environment demand for this technology asset [1] and a growing demand for on youth academy sports in USA that will only fuirther my desire to create a 
supportive tool to meet those standards. Entering data into a digital format and eliminating handwritten data sheets [14] for youth coaches and its players should create an optimization of coaching, parental guidance, and overall team performance.

While searching for the most profitable solution to the app design, we considered allocating resources that balanced the cost of testing multiple designs against the potential profits resulted [15]. Because we collected positive results from concept testing, such as voice of the customer (VOC) [16], user analysis, conjoint analysis, Kano methods, and Pugh concept selection, we concluded that our target market expressed on page ten, will more than absorb product placement. By using computer systems, through their ability to rapidly store, manipulate and communicate multimedia information, I will offer multi-dimensional distance practicing environments. For an extent use of online learning and offline individual work will more than create interaction and simulation [17] off my mobile Smart Sport application. Supported by Yueh-Min I can assure my users that the advanced electronic device applied on education will not only create a better learning environment for students, but also enhance their learning motivation [18].

I concluded that my app development will be a process of social integration between my clients (coaches and soccer players), with the objective to create a common workplace to solve their needs. Also, we conclude that there must be a solid fundamental training program based on rewarding for the users to have the motivation in becoming better learners. This evaluation research on the Smart Sport mobile app development proved that this extrinsic motivation influence the self-perception of competence and selfaffirmation of the users [19]. Using words from [20] to state that people's attention spans are shrinking, I reinforce the need for development of an app that manages objects and moves around inside virtual environments. I conclude only Virtual Reality can allow users to travel to places they wouldn't otherwise be able to see. I also conclude that the person who has control over its own directions, have a better desire to keep on learning and leveraging if it is the master of its progress. Finally, I have to agree with Harrison, Haruvy, and Rutstr stating that it is clear that virtual words have the ability to coordinate and allow the user to be present at multiple places instantly and at the same time [21].

\section{RESEARCH METHOD}

\section{A. Review Centric Method}

The Research Method used in this paper follows the review centric research [22]. Recently combining research methods e.g. [23] p. 112 became increasingly important in particular when pursuing the goal of gaining competitive advantage in the mobile application industry, facing an increasing demand for electronic devices dynamics inside classrooms and outside sports' fields [24] p. 613." One form for “developing new theoretical insights" [22] p. 506 is the review centric research approach in which a researcher reviews “existing theory and research" [22] p. 506, but the argument can be made that we also can include case study research findings that are based on the real world observation of practitioners and organizations e.g.[24, 25]. In the research presented here the focus is on combining the most important findings on mobile application elements based on both hedonic and utilitarian motivations. The group of hedonic elements deals with the forms, drawings, and social elements. The utilitarian elements group deals with the information and structural parts. Both findings suggest practical guidelines for companies to build apps that will successfully attend consumers' needs [8]. The first group are the students, for example, if students struggle to understand an in-class exercise, then they will be able to retrieve that assignment later on their own mobile devices and review and practice their exercises [26]. The second groups, are the athletes, with an extrinsic motivation influencing their self-perception of competence and their self-affirmation [19, 27]. Those elements I have identified in the academic literature based on which I determine that using computer systems, through their ability to rapidly store, manipulate and communicate multimedia information, would allow users to emerge in a multi-dimensional distance practicing environments [17], education not only creates a better learning environment for students but also enhances their learning motivation [18]. This theory advances our understanding that the mobile applications development is producing a new class of innovators, creators and producers in our society [7, 22] p. 507”. In this study I identify the most important benefits of developing mobile applications aids the workforce and the classrooms, and also permits faster transactions, wireless communication, and better job performances [27] help in the current business or organizational situation to build our mobile application to accomplish the top market share in coaching related apps. My research approach incorporates the "interpretive paradigm" in which a rich description of each factor in our current academic or athletic context is established [24] p. 615.

A comprehensive literature review on innovation and e-learning technology created a theoretical foundation of the paper. Using the novel theoretical insight, several different approaches in gathering manuscripts, articles, and models to build up my idea clearly. Inspired by past discussions and directions that provided a synthesis and a convenient repository for existing knowledge, a model was developed and evaluated using interviews to advance our understanding of mobile app development relevant to manufacturing organizations. This is an asset topic as the recent increasing demand for mobile apps, virtual reality devices, and self-coaching appears to be fairly attractive. A new model is presented to encapsulate highly dynamic interaction of technology innovation and communication to provide results that reflect on the fast-paced networking behavior and its implications on self-learning.

The research methods used in this study follows the principles outlined by [22]. It is a comprehensive literature review on mobile application development. Over one hundred articles have been reviewed in relevant journals such as JSTOR, ABI/Inform, and Academic Search Premier, which created a theoretical foundation of the paper. Four methods are for 
synthesizing education, social media network, motivation \& rewards, and virtual reality as essential for mobile application development [28, 29]. The contribution of the study is intended to review and summarize the theoretical and empirical knowledge that should further our theoretical understanding over the mobile app phenomenon. In addition, this theoretical integration should mirror a complex network among special concepts in both conception and substantial grounds. [22].

\section{B. Pillars of Mobile Application Development}

The research that has been developed in regard of the design of mobile applications is rich in detail and information. It is easy to understand that a number of factors must be considered during the development process in order for the mobile application to be effective. To create a technology up to date device, effective and flexible to the fast-pace demographic demand, it is key to invest in a complete market research, followed by a detailed product specifications, and summarized by an illustrative flowchart. The optimization of tasks and the ability of the users (workers/students) are key design requirements that must be aimed by all producers of mobile apps. I definitely agree that there is an entire enterprise environment demand for this technology asset [1]. For example, if students struggle to understand an in-class exercise, then they will be able to retrieve that assignment later on their own mobile devices and review and practice their exercises [26]. Also, I believe that mobile devices can not only affect the users themselves, but also provide the manufacturers back with a network of commerce. Talking about commercial transactions and easier methods of payments over mobile networks is a key reason why this technology is taking up the market [30] and many companies are creating virtual stores in their apps. We need to consider not only the specifics benefits of developing mobile applications that aid the workforce and the classrooms, but also the consequences in the society in overall: faster transactions, wireless communication, and better job performances [27]. Entering data into a digital format and eliminating handwritten data sheets [14] should be considered the "reinvention of the wheel" in the 21th Century. I can only agree with the idea that mobile applications development is producing a new class of innovators, creators and producers in our society [7].

\section{DISCUSSION}

\section{A. Education \& Learning}

The research about mobile application impact on learning is a matter of great interest to me because I want to be able to influence young soccer players to practice their skills outside the soccer lessons with an app that I will develop. Education and sports are key to nurture children with the best opportunities in life and educate them in a competitive and responsible setting. My thoughts can be sustained by the idea that since the creation of the first educational mobile apps, students can learn the knowledge and access the information anytime and anywhere without too much additional efforts [31]. Also, my research can be supported by any point stated by Evrim, Yueh-Min, and Russell, Elizabeth, Ray, \& Peter. First, I started by line of thoughts based on the concept that extended classroom interaction to other locations via communication networks [29] is highly effective to eager apprentices. Second, Smart Sport App would have the potential to provide multi-dimensional distance practicing environments, aligning coaches in one side and players on the other side of the network. This is possible because computers can rapidly store, manipulate and communicate multimedia information. The app would use online learning styles and offline individual work to create interaction and simulation [20] off my mobile application. Also, I agree with Yueh-Min when he states that the advanced mobile device application on education not only create a better learning environment for students but also enhance their learning motivation [21]. Motivation to learn is the key outcome to any professor, because there is no willing, nor capability to absorb information better performed when the student is actually interested in obtaining it. Finally, I must agree with Russell, because an ideal education tool coming from a mobile device is expected to rapidly store, manipulate and communicate multimedia information, just to provide a multi-dimensional distance teaching opportunity [20]. The success of using mobile applications as an education tool will be directly related to the ability of the manufacturer to explore the production and delivery of quick, online data, and how it will capture the users' motivation to learn and practice its exercises in the distance. The mobile development is directly tied to education by three main variables: Quick delivery of content; online exercises; and e-learning. An online-based learning system offers more benefits than traditional learning channels. It mainly provides a time, user group size, and geographical location in an independent learning platform. It also compresses a vast amount of Internet Web sites and deliver it to students in a very low data charge [32]. Also, the 'collective face wants' of the online community led to the creation of an online space in which participants were supported by their peers to do 'being critical' [33], online exercises would foster learning by increasing peer pressure when the results were posted online and allowed comparison among users. E-learning opens up new frontiers for professional learning, supports knowledge generation and management [34].

\section{B. Social Media Network}

The research done involving social media network and its role in mobile application development is mainly centered on how well the device will allow its end-users to receive and feedback the sender with communication and quick data exchange. For example, if my mobile app is designed to soccer players willing to practice outside lessons, and post their progress in their personal networks, my app should be developed on the premise of that specific goal [35]. Being socially integrated through online mass communication is a premise of an online network capable to retain users, create online forums, distribute campaigns and unify globalization. Just as [36] proposed, it should be a process of social integration between my clients (coaches and soccer players), with the objective to create a common workplace to solve the athlete skills' problems and provide them back with their coaches' solutions. I agree with [13] when he states that technology is as much a product of social construction as of technical innovation, and this evaluation research is 
designed to define my social construction goal as the leveraging of soccer playing on the distance, at any time. If I have to restate [37] phrase, I will apply the concept of the mobile network's transformation from a voice-only platform to a complete infrastructure that offers both voice and data services (videos, lessons, social media posts). Also, we know that young people enjoy technology as much as sports, so why not align both at the same device? As [38] mentioned, I can gain my competitive advantage on the premise that mobile applications are the new assets for communication and collaboration among young people, on the daily basis. Finally, I believe it can all be summed up on [39] talking about how social media's immense popularity applies a vast reach and empowers advocacy groups to connect with multiple individuals: the more people I get to post their feedback and soccer skills videos, the more engaged the other part of the end-users will be to use their social media channel on my mobile app.

Social networks are important for learning because they provide the biggest platform for individual's to interact with other people, by accessing their free information on behavior and cognitive actions online [40]. Social media, such as Facebook and Twitter, have become extremely popular. However, only a tiny proportion of these sharing units trigger any type of knowledge exchange that is ultimately beneficial to the users [41]. The app to be developed intend to trigger a content valuable enough for its academic and athletic substance and make a change in total society's welfare.

Finally, the last sub-variable is a premise of the social media successful influence over the application development. One of the biggest assets of mobile apps is its capacity to load and deliver data content faster than any other platform. According to [42], it also deals with the evaluation of the speed of the application type server-client and functionality of the application operating system. It would all be possible to occur in a fast-paced tempo thanks to the modern Internet communications standards.

\section{Motivation \& Rewards}

The research conducted about motivation and rewarding in terms of mobile application development is focused on transforming the learning process the app users would experience. We know that coaches and players are the users of the mobile application, and they must set goals to develop a specific under practiced skill as the improved outcome. I agree that there must be a solid fundamental training program based on rewarding the users in place for them so that they have an opportunity to become more motivated to work on becoming better soccer players. I also agree that this extrinsic motivation can influence the self-perception of competence and self-affirmation of the users [15]. It takes experience and efficiency to accomplish the special skills required to be competent inside the field, but if the mobile app provides its users with rewards such as videos from former professional soccer players congratulating the pupils, as well as, tickets to games every time a new level is achieved, we will accomplish our objective in developing this app. I feel that these athletic skills must be maintained over time by the coaches, and constant performance testing followed by rewarding would clearly be an accurate tester of the competency of their players (or pupils). As the authors Kremer, Miguel, and Thornton (2009) discussed, in many education systems, the students who perform well on exams covering one level of the studies would most likely receive free access to the following level as a matter of reward for their performance [43]. Myself included, as both a student and a player, I always needed some sort of reward in order to keep myself motivated to progress. Enomoto (2011) provides us with a real example of a self-motivation system: he supposes someone trying to win a tennis match. According to his logic, if that person is an experienced player, it may plan long-term tactics for six-game sets maximizing the concentration and effort in the most critical games, in order to maintain an advantage over the opponent and therefore reserve resources for the other games of the set and match. On the contrary, he explains, if the person is instead a beginner, it will probably just concentrate on winning each single game and will be exhausted halfway through the match. He concludes his thoughts addressing that long-term reward values for individual actions is a learned intelligence for the successful achievement of distant goals [44].

We also have to consider what Kowitz (1959) set different definitions for long term rewards or stimulation and motivation. For Kowitz, all the way back in those days, on one side stimulation was seen as a general affective arousal, which the teacher can obviously develop in his students in the educational situation. And on the other side, motivation would go beyond general affective arousal to orient the student toward a specific activity, which, it was assumed, would result in the desired learning [45]. I also believe in punishment as effective strategy to make myself perform better, as cited [46], but I do not believe punishment works for everyone, thus I will not count on punishment in my mobile app development. I think that the fundamental concept behind the training process is the overall performance enhancement based on the final outcome as motivation. The motivation concept must be carefully taken into consideration during the mobile app development because they are part of the main idea behind why athletes will purchase the app: better performances and self-determination. We observe motivation working as a favorable asset to our app, when we observed Cassandra (8 years old) constantly doing her soccer assignments after the coach promise her two stars. The situation was different when he only told her to do it. Finally, we must consider the study of Pallak, Costomiris, Sroka, and Pittman (1982) stating that the experience of drawing to earn a reward apparently led children to view the activity as a means to an outcome, rather than an outcome itself. Rewards coming from external sources thus seemed to supplant whatever intrinsic rewards an activity provided. As a result, the activity was unlikely to be performed unless external rewards were available [47]. A present study developed by Nikou in Computers in Human Behavior [48], revealed important justification for my correlation between motivation and mobile app development: it states that the analysis of both pre- and post-motivation tests shows a more positive motivational orientation when computers and mobile devices are being used as delivery mediums. Also, a student evaluation implemented after the experimental phase of the procedure showed a significant increase in education leveraging for low-achieving students who were tested on their mobile and computer-based assessment [48]. The positive effects of computers and mobile devices on students' learning motivation suggest that they can be used as a promising alternative to paper and pencil assessment 
procedures. Furthermore, a study conducted between urban and suburban school psychologists in terms of their motivation and self-regulation assessment beliefs, practices, and professional development needs, proved that these urban and suburban users found motivation and selfassessment referrals on a significant frequent basis, valued these processes, and were very interested in professional growth training [49].

\section{Virtual Reality}

The effect of virtual reality is gained by skillful readers each time they engage the printed word [50]. I chose to research about Virtual Reality influence over Mobile Application development, because of the success of the app called Pokemon Go. I believe Pokemon Go have stepped out from other app games because it mixes virtual world with reality. As an example, the player would walk around the city (real) looking for Pokemons (virtual). Everything about these technologies of virtual reality emphasize audience interaction, immersion, or participation over watching from a single vantage point [51]. The research that has been done involving Virtual Reality, because it has revolutionized the whole application market. VR is therefore a keystone in mobile application development because it is now centered on bringing great competitive advantage to the product. The future of mobile application is VR. We all feel more involved in a game or app that would allow us to mix daily life and virtual reality. For example, in my app, once the player feels that it can perform a practice, submit his video (real), and receive a video from a soccer star such as Cristiano Ronaldo (virtual) talking to it, it would feel very engaged in its practice and would use the app more often. Indeed, I can be justified by what [16] stated: people, whose attention spans are shrinking, could become inserted by managing objects and moving around in virtual environments. Virtual Reality would allow them to travel to places they would not otherwise be able to see. They could conduct experiments that they could not afford without simulation, and they could enter imaginary realms [16]. I also believe that the person who has control over its own directions, have a better desire to keep on learning and leveraging if it is the master of its progress. Finally, I have to agree with Harrison, Haruvy, and Rutstr stating that it is clear that virtual words have the ability to coordinate and allow the user to be present at multiple places instantly and at the same time [17]. In fact, a question can be posed with a call for us to try understanding VR as a measurement of society's inner thoughts, interests, fears and needs [52]; and the sooner we deal with it and develop answers from our questions, the best benefits can be taken from VR.

I believe that this could be one of the most critical elements of the mobile application design. In fact, there is no such thing as a possible app design that copes with the increasing market demand for Virtual Reality dimensions.

The greatest asset of virtual worlds is the capability to double the user identity. Virtual Reality is capable of change student's behavior by giving them access to an avatar [53]. Immersion in another world, therefore increases applicability of education, it facilitates the teacher's job in trying explaining a content by easy illustration, and it creates better understanding for students by performing content through an avatar. Virtual Reality worlds are also more attractive than 2-D worlds because it has a bigger perceptual measurement (the user receives clear illustrations of an action) than the second dimension platforms. Therapists' self-reported knowledge of virtual reality, theoretical orientation, and interest in using virtual reality were found to be associated with perceptual measures [54]. Finally, an insight on the outcomes of full management of reality allows me to cite [55]: Training in virtual environments (VEs) has the potential to establish mental models and task mastery while providing a safe environment in which to practice. Based on Figure 1, mobile application design is influenced by four factors. The factors are independent from themselves and only indicate proximity relation by the degree of investment applied, and the direct responsiveness created on the final goal. Findings could help teachers to take advantage of the combination of affordances of mobile technology and Apps that actually improve some aspects of learning practice [12].

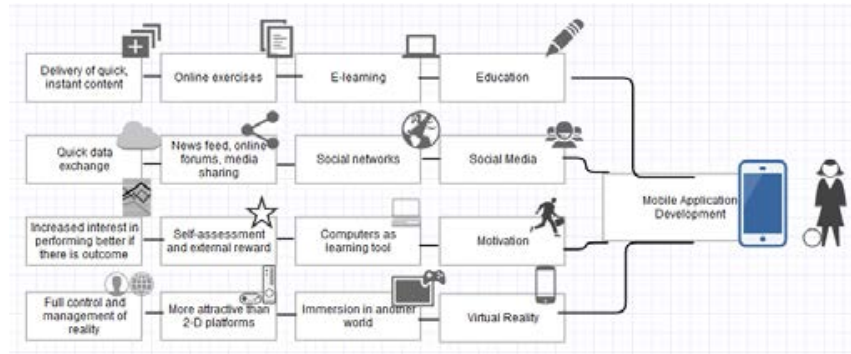

Fig. 1. The Four Factors of Influence to Mobile Application Development

\section{RESULT \& DISCUSSION}

This section analyses the results of the experiment. Strengths:

1. Educational tool: e-learning breaks down the walls on professional learning and supports knowledge development and management [34].

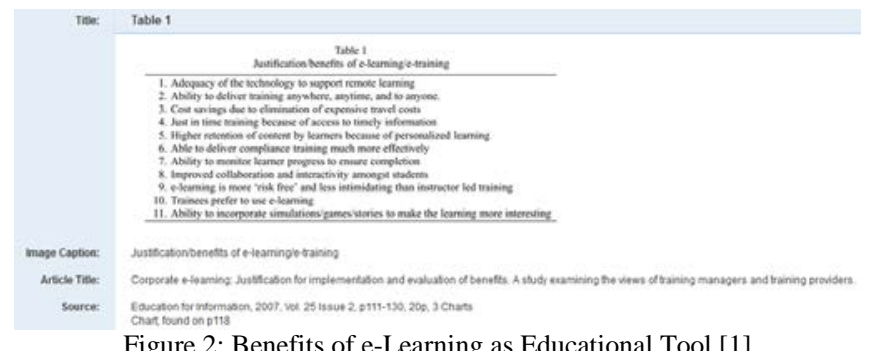

Figure 2: Benefits of e-Learning as Educational Tool [1]

2. Social Media: interacting and belonging to a bigger community, sharing information, engaging in constant education, mimicking the references, and branding [56].

3. Motivation: the use of mobile electronic devices or PCs in classroom has been effective in attracting and maintaining students' attention and increasing their desire to participate in educational activities [57].

4. Virtual Reality: virtual reality has proved to be effective in the treatment of many psychological difficulties, such as keeping interest in a nondynamic activity such as learning [54].

\section{CONCLUSION}

This is a timely topic because I want to develop an app that will aid children outside classroom, and athletes outside the fields. As the recent technology is changing abruptly, the 
demand to make an electronic device that assists people on their performances is key. A new model based on 70 articles researched is presented to provide results on how the variables such as learning process, motivation, social networks, and virtual reality shapes the digital development process, and how this mobile app will affect changes in behavior by creating external learning opportunities that would not exist otherwise.

Although the research has accomplished its objectives, there were some unavoidable limitations. The empirical data are limited to 70 qualitative articles and researches within the topic and its variables. The results of the study provide initial support for the use of a mobile app in-delivering digital coaching through both physical activity promotion and behavior changes, proving that well developed applications can be used to aid children with learning difficulties, young athletes seeking extra field coaching, and parents concerned with their children development.

\section{ACKNOWLEDGMENT}

The author wants to thank the other members of the Foundations of Product Management class at the University of Bridgeport for their help throughout the course; in particular Ph.D Christian Bach and Soumita Banerjee provided many useful discussions, teachings, and inspiration.

\section{REFERENCES}

[1] Gebauer, J. and M.J. Shaw, Success Factors and Impacts of Mobile Business Applications: Results from a Mobile e-Procurement Study. International Journal of Electronic Commerce, 2004. 8(3): p. 19-41.

[2] Pocatilu, P., et al., An aggregate indicator for mobile application quality assessment. Turkish Journal of Electrical Engineering \& Computer Sciences, 2015. 23(4): p. 956-973.

[3] Gatautis, R. and E. Vaiciukynaite, A Taxonomy of Mobile Application Elements: a Literature Review. Proceedings of the Multidisciplinary Academic Conference, 2015: p. 349-349.

[4] Jayaram, D., A.K. Manrai, and L.A. Manrai, Effective use of marketing technology in Eastern Europe: Web analytics, socia media, customer analytics, digital campaigns and mobile applications. Uso eficaz de la tecnología de marketing en Europa de Este: analíticas de web, medios sociales, analítica de clientes, campañas digitales y aplicaciones móviles., 2015. 20(39): p. 118132.

[5] Charland, A. and B. Leroux, Mobile Application Development: Web vs. Native. Communications of the ACM, 2011. 54(5): p. 49-53.

[6] King, A.C., et al., Effects of Three Motivationally Targeted Mobile Device Applications on Initial Physical Activity and Sedentary Behavior Change in Midlife and Older Adults: A Randomized Trial. PLoS ONE, 2016. 11(6): p. 1-16.

[7] Agnes, K.-H., Learning Cultures on the Move: Where are we heading? Journal of Educational Technology \& Society, 2010. 13(4): p. 4-14.

[8] Kang, S.J., J.-P. Ha, and M.E. Hambrick, A Mixed-Method Approach to Exploring the Motives of Sport-Related Mobile Applications Among College Students. Journal of Sport Management, 2015. 29(3): p. 272-290.

[9] Hoehle, H. and V. Venkatesh, MOBILE APPLICATION USABILITY: CONCEPTUALIZATION AND INSTRUMENT DEVELOPMENT. MIS Quarterly, 2015. 39(2): p. 435-A12.

[10] Majchrzycka, A. and A. Poniszewska-MaraŃDa, Secure development model for mobile applications. Bulletin of the Polish Academy of Sciences: Technical Sciences, 2016. 64(3): p. 495-503.

[11] Pelletier, J.-F., et al., No personalization without participation: on the active contribution of psychiatric patients to the development of a mobile application for mental health. BMC Medical Informatics \& Decision Making, 2013. 13(1): p. 1-8.

[12] Domingo, M.G. and A.B. Garganté, Exploring the use of educational technology in primary education: Teachers' perception of mobile technology learning impacts and applications' use in the classroom. Computers in Human Behavior, 2016. 56: p. 21-28.
[13] McBride, N., Actor-Network Theory and the Adoption of Mobile Communications. Geography, 2003. 88(4): p. 266-276.

[14] Heather, L.B., et al., Mobile Application for Wildlife Capture\&\#x2013;Mark\&\#x2013;Recapture Data Collection and Query. Wildlife Society Bulletin (2011-), 2013. 37(4): p. 838-845.

[15] Deci, E.L., R. Koestner, and R.M. Ryan, Extrinsic Rewards and Intrinsic Motivation in Education: Reconsidered Once Again. Review of Educational Research, 2001. 71(1): p. 1-27.

[16] Nathaniel, B., The Virtues and Vices of Virtual Reality. Design Quarterly, 1993(159): p. 38-44.

[17] Harrison, G.W., et al., Remarks on Virtual World and Virtual Reality Experiments. Southern Economic Journal, 2011. 78(1): p. 87-94.

[18] Dahan, E. and H. Mendelson, An Extreme-Value Model of Concept Testing. Management Science, 2001. 47(1): p. 102-116.

[19] Griffin, A. and J.R. Hauser, The Voice of the Customer. Marketing Science, 1993. 12(1): p. 1-27.

[20] Russell, J., et al., The learning computer: low bandwidth tool that bridges digital divide. Journal of Educational Technology \& Society, 2007. 10(4): p. 143-155.

[21] Yueh-Min, H., H. Wu-Yuin, and C. Kuo-En, Guest Editorial \&\#x2013; Innovations in Designing Mobile Learning Applications. Journal of Educational Technology \& Society, 2010. 13(3): p. 1-2.

[22] LePine, J.A. and A. Wilcox-King, Developing novel theoretical insight from reviews of existing theory and research. Academy of Management Review, 2010. 35(4): p. 506-509.

[23] Gable, G.G., Integrating Case Study and Survey Research Methods: An Example in Information Systems. European Journal of Information Systems, 1994. 3(2): p. 112-126.

[24] Dyer, G.W.J. and A.L. Wilkins, Better stories, not better constructs, to generate better theory: A rejoinder to Eisenhardt. Academy of Management Review, 1991. 16(3): p. 613-619.

[25] Eisenhardt, K.M., Building Theories from case study research. Academy of Management Review, 1989. 14(4): p. 532-550.

[26] Jennifer, J.W., N.B. Heidi, and P.R. Michael, Apps for Teaching, Not Just Reviewing. Teaching Children Mathematics, 2015. 21(7): p. 438-441.

[27] Liang, T.-P. and C.-P. Wei, Introduction to the Special Issue: Mobile Commerce Applications. International Journal of Electronic Commerce, 2004. 8(3): p. 7-17.

[28] Kim, K., et al., Youth-centered design and usage results of the iN Touch mobile self-management program for overweight/obesity. Personal \& Ubiquitous Computing, 2015. 19(1): p. 59-68.

[29] Evrim, B., A Review of Research on Mobile Learning in Teacher Education. Journal of Educational Technology \& Society, 2014. 17(4): p. 17-32

[30] Mylonopoulos, N.A. and G.I. Doukidis, Introduction to the Special Issue: Mobile Business: Technological Pluralism, Social Assimilation, and Growth. International Journal of Electronic Commerce, 2003. 8(1): p. 5-22.

[31] Yu-Lin, J., et al., The Add-on Impact of Mobile Applications in Learning Strategies: A Review Study. Journal of Educational Technology \& Society, 2010. 13(3): p. 3-11.

[32] Li, F.W.B. and R.W.H. Lau, On-Demand E-Learning Content Delivery Over the Internet. International Journal of Distance Education Technologies, 2006. 4(1): p. 46-55.

[33] Watson, C., et al., Criticality and the exercise of politeness in online spaces for professional learning. Internet \& Higher Education, 2016. 31: p. 43-51.

[34] Newton, R. and N. Doonga, Corporate e-learning: Justification for implementation and evaluation of benefits. A study examining the views of training managers and training providers. Education for Information, 2007. 25(2): p. 111-130.

[35] DeCoster, E., The Library Quarterly: Information, Community, Policy, 2012. 82(1): p. 101-103.

[36] Allen, J.P., The Evolution of New Mobile Applications: A Sociotechnical Perspective. International Journal of Electronic Commerce, 2003. 8(1): p. 23-36.

[37] Kavassalis, P., et al., Mobile Permission Marketing: Framing the Market Inquiry. International Journal of Electronic Commerce, 2003. 8(1): p. 55-79.

[38] Marcelo, M. and S. Daniel, Anytime, Anywhere Learning Supported by Smart Phones: Experiences and Results from the MUSIS Project. Journal of Educational Technology \& Society, 2007. 10(4): p. 62-70.

[39] Jonathan, A.O., Z. Paul, and L. Clifford, Advocacy 2.0: An Analysis of How Advocacy Groups in the United States Perceive and Use Social Media as Tools for Facilitating Civic Engagement and Collective Action. Journal of Information Policy, 2012. 2: p. 1-25.

[40] Bener, A.B., et al., Empirical Models of Social Learning in a Large, Evolving Network. PLoS ONE, 2016. 11(10): p. 1-20. 
[41] Ma, W.W.K. and A. Chan, Knowledge sharing and social media: Altruism, perceived online attachment motivation, and perceived online relationship commitment. Computers in Human Behavior, 2014. 39: p. 51-58.

[42] Petrucha, J., R. Jurča, and D. Bartoněk, DESIGN OF DATABASE APPLICATIONS IN MOBILE DEVICES WITH OS ANDROID. Proceedings of the International Multidisciplinary Scientific GeoConference SGEM, 2016. 1: p. 173-180.

[43] Kremer, M., E. Miguel, and R. Thornton, INCENTIVES TO LEARN. The Review of Economics and Statistics, 2009. 91(3): p. 437-456.

[44] Enomoto, K., et al., Dopamine neurons learn to encode the longterm value of multiple future rewards. Proceedings of the National Academy of Sciences of the United States of America, 2011. 108(37): p. 15462-15467.

[45] Kowitz, G.T., The Motive to Learn. The Elementary School Journal, 1959. 59(7): p. 380-385.

[46] Entwistle, N., Motivation to Learn: Conceptualisations and Practicalities. British Journal of Educational Studies, 1987. 35(2): p. 129-148.

[47] Pallak, S.R., et al., School Experience, Reward Characteristics, and Intrinsic Motivation. Child Development, 1982. 53(5): p. 1382-1391.

[48] Nikou, S.A. and A.A. Economides, The impact of paper-based, computer-based and mobile-based self-assessment on students' science motivation and achievement. Computers in Human Behavior, 2016. 55: p. 1241-1248.

[49] Cleary, T.J., A. Gubi, and M.V. Prescott, Motivation and selfregulation assessments: Professional practices and needs of school psychologists. Psychology in the Schools, 2010. 47(10): p. 985-1002.

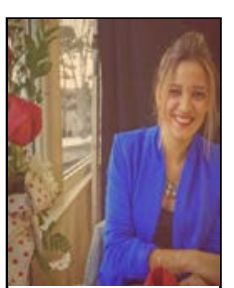

Amanda Miranda Cunha de Moura, was born in Belo Horizonte, Brazil in October 13, 1993. Moura obtained her bachelor's degree from the Ernest C. Trefz School of Business, University of Bridgeport in 2016. She is currently a full-time student-athlete pursuing her M.B.A in Management under the supervision of Ph.D Information Science Christian Bach.

Amanda's brother, Rafael Moura, is a star striker for the Serié A Brazilian Club Figueirense. Amanda played professionally for Atletico Mineiro, one of Brazil's major Clubs, where her team won the state championship three times competing at the national level against Santos and their star Marta. Amanda established a professional career in a women's soccer in Brazil despite social prejudice and lack of support for women's teams from the clubs and sponsors.

Amanda advocated for women in sports and society in a speech before the Brazil National Congress and was recognized with a Clara Zetkin medal for her work on behalf of women's rights. In the U.S., Amanda is pursuing both her education and soccer, an option that is not available in Brazil. In addition, Amanda has worked with a leading player management company based in Brazil that supports Brazilian player's aspirations to play professionally in the United States.
[50] De La, P., xf, and K. a McCook, The First Virtual Reality. American Libraries, 1993. 24(7): p. 626-628.

[51] deLahunta, S., Virtual Reality and Performance. PAJ: A Journal of Performance and Art, 2002. 24(1): p. 105-114.

[52] Shannon, S., The Chrome Age: Dawn of Virtual Reality. Leonardo, 1995. 28(5): p. 369-380.

[53] Garrido-Iñigo, P. and F. Rodríguez-Moreno, The reality of virtual worlds: pros and cons of their application to foreign language teaching. Interactive Learning Environments, 2015. 23(4): p. 453470.

[54] Segal, R., M. Bhatia, and M. Drapeau, Therapists' Perception of Benefits and Costs of Using Virtual Reality Treatments. CyberPsychology, Behavior \& Social Networking, 2011. 14(1/2): p. 29-34.

[55] Serge, S.R., et al., The effects of static and adaptive performance feedback in game-based training. Computers in Human Behavior, 2013. 29(3): p. 1150-1158.

[56] Panahi, S., J. Watson, and H. Partridge, Social media and physicians: Exploring the benefits and challenges. Health Informatics Journal, 2016. 22(2): p. 99-112.

[57] Hung, C.-Y., J.C.-Y. Sun, and P.-T. Yu, The benefits of a challenge: student motivation and flow experience in tablet-PC-game-based learning. Interactive Learning Environments, 2015. 23(2): p. 172190. 